\title{
Okul Öncesi Çocuklarda Mizacın Öğretmen-Öğrenci İlişkisini Yordama Düzeyi ile Bazı Değişkenler Açısından İncelenmesi
}

DOI: $10.26466 /$ opus. 966493

\author{
Sabiha Eren* \\ * Araş. Gör.,Uşak Üniversitesi,Eğitim Fakültesi, Uşak/Türkiye \\ E-Posta: sabiha.eren@usak.edu.tr \\ ORCID: $\underline{0000-0002-2599-3913}$
}

\begin{abstract}
Öz
Bu çalışmanın amacı, okul öncesi eğitim kurumuna devam eden ve 4-6 yaş grubu çocuklarda mizaç ve öğretmen-çocuk ilişkisinin yordayıcılı̆̆ın araştırmak ve mizaç alt boyutlarının cinsiyete, ebeveyn eğitim düzeyine göre değişip değişmediğini belirlemektir. Çalışma için gerekli etik kurul izni alınmıştır. Çalışma grubunu 168'i kız 146'si erkek olmak üzere toplam 314 çocuğun ebeveynleri ve öğretmenleri oluşturmaktadır. Çalışma verileri 2020-2021 eğitim öğretim yılı bahar döneminde, Uşak il merkezinde bulunan Milli Eğitim Bakanlığına bağhı anaokulları, anasınıfları ve özel okullardan toplanmıştır. Veriler Çocuklar için Kısa Mizaç Ölçeği ve Öğretmen-öğrenci ilişsisi ölçekleriyle toplanmıştır. Verilerin analizinde betimsel istatistikler, bağımsız örneklem t-testi, ANOVA ve regresyon analizi kullanılmıştır. Araştırma sonuçlarına göre mizaç ile cinsiyet ve anne-baba eğitim durumu arasında iliş̧ki bulunmuştur. Araştırma bulgularından mizacin sebatkarlık alt boyutunda cinsiyete göre farklılık oluştuğunu göstermektedir. Mizaç alt boyutlarından sebatkarlık ve utangaçlı̆̆ın çatışmayı, sebatkarlık ve ritmikliğin yakınlığı anlamlı olarak yordadı̆̆̆ sonucuna ulaşılmıştır. Araştırmanın bulguları literatür ışı̆̆̊ında tartışılmış ve gelecek çalışmalar için önerilerde bulunulmuştur.
\end{abstract}

Anahtar Kelimeler: Öğretmen-Öğrenci Ilişkisi, Mizaç, Ebeveyn Ĕ̆itim Düzeyi. 


\title{
Investigation of Temperament in Preschool Children in terms of Predicting Level of Teacher-Student Relationship and Some Variables
}

\begin{abstract}
The aim of this study is to investigate the predictor of temperament and teacher-child relationship in children aged 4-6 attending pre-school education institutions and to determine whether temperament sub-dimensions vary according to gender and parental education level. Ethics committee approval was obtained for the study. The study group consists of parents and teachers of 314 children, 168 of whom are girls and 146 are boys. The study data were collected in the spring semester of the 2020-2021 academic year from kindergartens, nursery classes and private schools affiliated to the Ministry of National Education in the city center of Uşak. The data were collected with the Children's Short Temperament Scale and the teacher-student relationship scales. Descriptive statistics, independent sample t-test, ANOVA and regression analysis were used in the analysis of the data. According to the results of the research, a relationship was found between temperament, gender and educational status of parents. Research findings show that there is a gender difference in the perseverance sub-dimension of temperament. It was concluded that perseverance and shyness, which are sub-dimensions of temperament, significantly predicted conflict, and persistence and rhythmicity predicted closeness. The findings of the study were discussed in the light of the literature and suggestions were made for future studies.
\end{abstract}

Keywords: Teacher-Student Relationship, Temperament, Parental Education Level. 


\section{Giriş}

Okul öncesi eğitim, erken çocukluk dönemi çocuklarının akademik başarılarına, ilkokula uyum sağlamalarına, dil, bilişsel, fiziksel gelişimlerine katkı sağlamasının yanı sıra çocukların sosyal ve duygusal gelişiminde de kritik dönem olarak görülmektedir. Bu dönemde çocukların gelişimlerine ailelerinin yanı sıra öğretmenleri de katkı sağlamaktadır. Öğretmen çocuğun okula uyumu, alışkanlık kazanması, okulda eğlenmesi gibi birçok sorumluluk üstlenmektedir (Akt. Yoleri, 2016). Çocuklarla olumlu ilişkiler kuran, sıcak, rahat bir eğitim ortamı oluşturan öğretmenlerin yer aldığı sinıflarda kaliteli, üst düzeyde öğrenmenin gerçekleştiğini belirtilmektedir (Beahm, 2009; Işık, 2007).

Çocukların okulda yaşadıkları başarılar ve başarısızlıklar gelecekteki beklentilerini de şekillendirebilir. Özellikle çocukların öğretmenleriyle olan ilişkilerindeki başarı önem taşımaktadır. Öğretmenleriyle olumlu ilişkiler kurabilen çocuklar aynı zamanda öğretmenleriyle etkileşimleri sonucunda olumlu geribildirimler alabilmektedir. Çocuklar bu geribildirimleri içselleştirirler. Benzer şekilde olumsuz geribildirim alan çocuklarda bunları içselleştirmektedirler. Mevcut kanıtlar, öğretmen-çocuk ilişkilerinin sadece geçmişte saldırgan davranışlar gösteren çocuklar için koruyucu bir faktör olarak hizmet etmediğini, aynı zamanda olumlu ilişkilerin de çocukların gelişimini kolaylaştırdığını göstermiştir (Silver, 2005). Ayrıca öğretmenleriyle olumlu ilişkilere sahip olan çocukların sınıflarında yetkin davranış sergileme, öğrenmeye hazır olma belirtileri daha yüksektir (Rudasill, Rimm-Kaufmann, Justice, Pence, 2006). Hamre ve Pianta'nın (2001) çalışmasında öğretmenleriyle iyi ilişkiler içinde olan çocukların, olumsuz öğretmen-çocuk ilişkileri içinde olan çocuklara göre daha verimli akademik ve sosyal gelişim gösterdikleri sonucuna ulaşılmıştır.

Öğretmen çocuk ilişkisinin kalitesini etkileyen, öğretmenin ve çocuğun bireysel geçmişi, biyolojik faktörleri ve yaşadıkları deneyimler gibi birden çok değişken bulunmaktadır (Pianta, 1999). Çocuğun mizaç özellikleri de öğretmen çocuk ilişkisini etkileyen değişkenlerden biri olarak değerlendirilmektedir. Örneğin, yapılan araştırmalara göre cesur veya çekingen olmayan çocukların akranlarına göre daha fazla sosyal beceriye sahip ol- 
dukları ve bu nedenle öğretmenleriyle daha fazla etkileşime sahip oldukları bulunmuştur (Patrick, Yoon ve Murphy, 1995, Rimm-Kaufmann, Kagan, 2005).

Çocuklar kişiliklerinin temeli olan bazı mizaç özellikleriyle dünyaya gelirler. Bebeğin döllenmesinden itibaren mizacı üzerinde çevrenin etkisi görülmeye başlar. Annenin hamilelik döneminde kötü beslenmesinin, yaşadığ 1 stresin bebeğin mizacı üzerinde olumsuz etkileri görülmektedir. Kişiliğin biyolojik temeli olan mizaç; bireyin bebeklikte, çocuklukta, ergenlikte, yetişkinliğin ilk dönemlerinde bireyin yaşadığı deneyimlerle kişiliği oluşturmaktadır (Khatibi, Khormaee, 2016).

Mizaç yaşamın erken yıllarında görülen bireysel farklılıklardır. Bu farklılıklar aynı zamanda çocukların fiziksel ve sosyal çevresine gösterdikleri tepkileri ve çevrenin çocuklara olan tepkisini de şekillendirmektedir. Çocuğun doğuştan gelen mizacı dünya ile etkileşimlerini şekillendirir ve başkalarının ona verdiği tepkileri de etkiler (Bee, Boyd, 2009). Mizaç değişmeyen, yüksek devamlılık gösteren bir özellik olarak görülmektedir. Mizaç üzerine, çocuklar arasındaki uyaranlara tepki verme ile duygularını ve dikkatlerini düzenleme kapasiteleri gibi niteliklerdeki farklılıkların sosyal gelişim sürecini nasıl etkilediğinin anlaşılmasına zemin hazırlamaktadır (Thomas, Chess, Birch, Hertzig ve Korn, 1963).

Zor mizaç özellikleri incelendiğinde ise; erken çocukluk döneminde yüksek düzeyde antisosyal davranışlar evde, okulda ve toplumda sorunlu davranışları öngörmektedir (Côté ve ark. 2007). Ayrıntılı olarak, antisosyal davranışlar hem içselleştirme hem de dişsallaştırma davranış problemlerini içerir (Merrell 1993). Bu tür davranışların akranlar, ebeveynler ve öğretmenlerle olan ilişkiler üzerinde olumsuz sonuçları vardır (Doumen, Verschueren, Buyse, Germeijs, Luyckx, Soenens, 2008) ve olumlu akran ilişkileri oluşturmadaki bu zorluk, daha fazla dışsallaştırma davranışına yol açabilir (Masten 2006; Van Lier ve Koot 2010).

\section{Öğretmen-Çocuk İlişkisi ve Mizaç}

Mizaç kavramı, bireyin ilerleyen yaşantılarındaki işleyişi öngörmek için etkileşimsel bir bakış açısı bağlamında da incelenmiştir. Yani, mizaç olarak iş birliği yapmayan bir çocuk, çevrede muhtemelen olumsuz tepkiler 
yaşayabilir; bu tür olumsuz tepkiler de davranış sorunlarına neden olabilir. Bu hipoteze benzer bulgular okulda karşılaşılan sorunların nedenlerinden birininde zor mizaca sahip çocuklar olduğunu göstermektedir (Séguin ve MacDonald, 2018).

Çocukların davranışları çevreleri ile etkileşimli bir şekilde ilerlemektedir. Her ne kadar çevre çocuğu etkilese de çocukların mizacı da bakıcıları, akranları ve öğretmenlerinden de aynı şekilde etkilenmektedir. Çocukların mizaç özellikleri etkileşim sürecinde oldukça aktif bir rol oynar (Thomas, Chess, Birch, 1968). Çocuklar yaşadıkları çevresel deneyimleri mizaçlarına göre yorumlamaktadırlar. Örneğin; endişeli ve sinirli çocuklar, yaşamlarındaki olumsuz olayları, olumsuz duyguları düşük düzeydeki çocuklara göre daha tehdit edici olarak algılama eğilimindedir (Shiner, 2005).

Çocukların mizacı, cinsiyeti gibi bazı değişkenler öğretmen-çocuk ilişkisinin kalitesini etkilemektedir (Rudasill, Rimm-Kufman, 2009). Öğretmen-çocuk ilişkilerinin kısmen öğretmenlerin öğrencilerin eğilimlerine ilişkin algıları tarafından şekillendirildiğini göstermektedir (Stuhlman ve Pianta, 2002). Öğretmenleriyle sıcak ve yakın ilişkiler yaşayan okul öncesi dönem çocuklarının daha az davranış sorunu sergiledikleri, akranlarına göre okuldan daha çok keyif aldıkları ve daha iyi akademik performans sergiledikleri görülmektedir (Masburn ve Pianta, 2006). Diğer taraftan bazı mizaç özelliklerine sahip çocuklar okula başarılı bir şekilde uyum sağlayabilmekte ve öğretmenler de farkında olmadan bu çocuklara daha fazla akademik başarı sağlamaları konusunda güven verebilmektedir (Stuhlman, Pianta, 2002). Dört yaşındaki çocuklarla yapılan bir araştırmada düşük tepkiselliğe sahip çocuklar sınıfta kendiliğinden konuşmaya başlarken, yüksek tepkiselliğe sahip çocukların sessizce gözlem yaparak yalnız kaldıkları bulunmuştur (Kagan, Snidman ve Arcus, 1992).

Öğretmenlerin uyumlu çocuklarla yakın ilişkileri varken, 1srarcı, dikkati çabuk dağılan çocuklarla daha çatışmacı ilişkileri vardır (Ören, Jones, 2009). Flynn (2000)'ın yaptığı mizaç, öğretmen-çocuk ilişkisi araştırmasına özel gereksinimli çocuklar ve bu çocukların öğretmenleri katılmıştır. Çalışma sonucunda öğretmen çocuk ilişkisinin yakınlık boyutu ile mizacın esneklik boyutu arasında olumlu yönde ilişki bulunmuştur. Benzer şekilde, Keogh ve Burstein (1988), yüksek görev yönelimi, yüksek esneklik (sosyallik) ve düşük tepkisellik gibi mizaç özelliklerinin, sınıf etkinlikleri 
daha az yapılandırıldığında çocukların öğretmenleri ve akranlarıyla etkileşimleriyle önemli ölçüde ilişkili olduğunu göstermiştir. Bu mizaç özelliklerinin, dikkat dağınıklıklarının daha sık olduğu ancak müdahalenin ve yapılandırılmış etkinliklerin daha az olduğu ortamlarda çocukların odaklanmış ve görev başında kalmalarına yardımcı olduğu görülmektedir.

Öğretmenler, besleyici ve destekleyici ortamlar sağlayarak mizaç aç1sından risk altındaki çocuklarla yüksek yakınlık düşük çatışma gibi olumlu ilişkiler oluşturduğunda, çocuklardan daha iyi sosyal çıtılar alınmaktadır (Rudasill vd., 2013). Çocukların öğretmenleriyle erken dönemde kurduklar ilişkileri, sosyal yeterliliğin gelişiminde kritik bir rol oynamaktadır. Örneğin, olumlu öğretmen-çocuk ilişkileri, risk altında olabilecek küçük çocukların sorunlu sosyal etkileşimleri için koruyucu olabilir (Acar vd., 2018). Öte yandan, çocukların öğretmenleriyle olan zayıf ilişkileri, çocukların akranlarıyla olan problem davranışlarını etkileyebilir. Yani, öğretmenler ve çocuklar arasındaki düşük düzeyde yakınlık ve yüksek düzeyde çatışma, utangaçlık ile sosyal yeterlilik veya akranlarla saldırgan davranış arasındaki ilişkileri güçlendirebilir. Örneğin, Sette ve arkadaşlarının (2014), İtalyan okul öncesi sınıflarında yaptıkları çalışma sonucunda öğretmen yakınlığı düşük olan çocuklar için utangaçlığın öğretmen dereceli sosyal yeterlilik ile negatif, akran reddi ile pozitif ilişkili olduğunu bulmuşlardır.

\section{Amaç ve Önem}

Gelişim psikolojisi; yapılan araştırmalarla soruna katkıda bulunan özgün çalışmalara, sonuçlar ile katkı sağlayanlar arasındaki etkileşimlere yararlı bir çerçeve sağlamaktadır. Bu çalışmada çocuğun etkileşimsel sonuçlarını değerlendirmek için farklı yaklaşımlar belirlenmiştir. Bunlardan ilki, yukarıda tartışıldığ gibi çocuğun çevreyle olan etkileşimlerinden biri olan öğretmen-çocuk ilişkisi, bir diğeri çocuğun doğuştan getirdiği ancak çevrenin etkisiyle değişik özelliklerinin ortaya çıktığı mizaç ve son olarak da istatistiksel bir yaklaşım kullanılmıştrı. Mevcut literatüre dayanarak çocuğun mizaç özelliklerinin öğretmen-çocuk ilişkisindeki yakınlık ve çatışma üzerinde rol oynayacağı varsayılmıştır. Yapılan bu çalışmayla cinsiyet, anne-baba eğitim durumu gibi bazı değişkenlerin mizaç ve öğretmen-çocuk ilişkisine etkisi ve mizaç ile öğretmen-çocuk ilişkisinin yordayıcı ve 
yordanan faktörler açısından incelenmesi amaçlanmaktadır. Bu kapsamda aşağıdaki sorulara yanıt aranmıştır;

1.Çocukların mizaç alt testlerinden elde ettikleri puan ortalamaları, çocukların;

Cinsiyetine

Annenin öğrenim durumuna

Babanın öğrenim durumuna göre farklılık göstermekte midir?

2.Çocukların mizaç özellikleri, öğretmen-çocuk ilişkisini yordamakta midır?

\section{Yöntem}

Katılımcılar: Bu araştırmanın katılımcılarını okul öncesi eğitim kurumuna devam eden ve normal gelişim gösteren 168'i kız 146'si erkek olmak üzere toplam 314 çocuğun ebeveynleri ve öğretmenleri oluşturmaktadır. Verilerin 157'si Milli Eğitime bağlı bağımsız anaokulu, 88'i anasınıfı ve 69'u özel okul olmak üzere 3 farklı okul türünden toplanmıştır. Çalışmaya katılan çocukların büyük çoğunluğunu (\%78,7) 5 yaş grubu oluşturmaktadır. Verilerin toplandığı annelerin $\% 45,2$ ve babaların $\% 43,9^{\prime}$ u lisans mezunudur.

\section{Ölçüm Araçları}

Öğretmen-öğrenci ilişki ölçeği: Pianta (2001) tarafından Amerika' da geliştirilen ve İtalya, Hollanda, Yunanistan, Norveç ve Çin'de uyarlama çalışmaları yapılan Öğretmen-Öğrenci İlişki ölçeğinin Türkiye uyarlaması Zorbaz, Özer, Gençtanırım-Kurt ve Ergene (2016) tarafından yapılmıştır. 46 öğretmenin 560 öğrenci için doldurdukları ölçekten elde edilen veriler sonucunda ölçeğin iki faktör (yakınlık ve çatışma) ve 23 maddeden oluştuğu belirlenmiştir. Güvenirlik çalışmaları kapsamında Cronbach Alfa katsayıları yakınlık altboyutu için .83; çatışma alt boyutu için .86 olduğu tespit edilmiştir. (Örneğin; "Öğrencinin bana karşı duyguları aniden değişebilir.", "Öğrenci hatasını düzelttiğimde incinir.", "Öğrenci benimle olan ilişkisine değer verir.", "Öğrenci duygu ve yaşantılarını benimle açık bir şekilde paylaşır.") 
Çocuklar için Kısa Mizaç Ölçeği: Prior, Sanson ve Oberklaid (1989) tarafından geliştirilen çocuklar için Kısa Mizaç Ölçeği'nin Türkçe versiyonu, Yağmurlu ve Sanson (2009) tarafından hazırlanmıştır ve Avustralya'da yaşayan 58 Türk çocuğun annelerine uygulanmıştır. Bu çalışmada, ölçeğin Türkçe versiyonunun iç tutarlık puanları sıcakkanlılık için .80, tepkisellik için .77, sebatkarlık için .76 ve ritmiklik icin .48 olarak bulunmuştur. Yağmurlu ve Altan'ın (2010) çalışmasında ise Çocuklar için Kısa Mizaç Ölçeği, yaşları 46 ile 70 ay arasında değişen Türk çocukların annelerine $(N=145)$ uygulanmıştır. Bu çalışmada örneklem grubu, İstanbul'da orta-üst sosyoekonomik düzey ailelere hizmet veren gündüz bakım evlerinden seçilmiştir. Ölçek güvenirliğinin, sıcakkanlılık için .75, tepkisellik için .69, sebatkarlık için .75 ve ritmiklik icin .63 değerleri ile kabul edilir sınırlar içinde olduğu sonucuna ulaşılmıştır.

\section{Verilerin Analizi}

Araştırma verileri toplanmadan önce Hacettepe Üniversitesi etik komisyonundan 9.03.2021 tarihli etik kurul izni alınmıştır. Araştırma verileri araştırmacı tarafından okullarda öğretmenlerle görüşülerek ve öğretmenler aracılığı ile ebeveynlerden elde edilmiştir. Öğretmenlere ÖğretmenÖğrenci İlişki Ölçeği, ebeveynlere Çocuklar için Kısa Mizaç Ölçeği uygulandıktan sonra eksiksiz olarak doldurulan 314 ölçek formu değerlendirilmeye tabi tutulmuştur.

Elde edilen verilerin analizi için yapılan normallik değerlendirmelerinde ölçeklerden elde edilen verilerin çarpıklık ve basıklık katsayıları incelenmiştir. Bu inceleme sonucunda Öğretmen-Öğrenci İlişki Ölçeği alt faktörleri olan yakınlık ve çatışma değişkenlerinin (ÇKYakınık=-0.216, BKYaknllk=-0.107; ÇK Çatışma $=0.615$, BKÇatışma=-0.344) ve Çocuklar için Kısa Mizaç Ölçeği alt faktörleri olan utangaçlık, sebatkârlık, ritmiklik ve tepkisellik değişkenlerinin (ÇKUtangaçlik=-0.219, BKUtangaçlik=-0.408; ÇKsebatkarlı $=-0.233$, BKsebatkarlk=-0.355; ÇKRitmiklik=0.015， BKRitmiklik=-0.515; ÇK Tepkisellik=0.417， BKTepkisellik=-0.518) normal dağıldığı görülmüsştür. Bu değişkenlerin normal dağılım göstermesi, sürekli ve eşit aralık ölçek düzeyinde olması sebebiyle parametrik testlerin kullanılması uygun görülmüştür. 
Çocuklar için Kısa Mizaç Ölçeği'nden elde edilen verilerin cinsiyete göre incelenmesinde bağımsız örneklemler için t-testi, anne-baba eğitim durumuna göre incelenmesinde ANOVA kullanılmıştır. Çocuklar için Kısa Mizaç Ölçeği'nin alt faktörlerinin Öğretmen-Öğrenci İlişki Ölçeği alt faktörlerini yordama düzeylerinin incelenmesi için regresyon analizi yapılmıştır. Çocuklar için Kısa Mizaç Ölçeği'nin alt faktörleri ile ÖğretmenÖğrenci İlişki Ölçeği alt faktörleri arasındaki ilişkiler Pearson momentler çarpımı korelasyon katsayısı ile incelenmiştir. Sonuçlar 0.05 ve 0.01 anlamlılık düzeylerinde değerlendirilmiştir.

\section{Bulgular}

Tablo 1. Değişkenlerin Alt Boyutlarına İlişkin Betimsel İstatistikler

\begin{tabular}{|c|c|c|c|c|c|c|}
\hline İstatistik & $\begin{array}{l}\text { ÇİKMÖ-Utangaç- } \\
\text { lik }\end{array}$ & $\begin{array}{l}\text { ÇİKMÖ-Se- } \\
\text { batkârlık }\end{array}$ & $\begin{array}{l}\text { ÇİKMÖ-Rit- } \\
\text { miklik }\end{array}$ & $\begin{array}{l}\text { ÇİKMÖ-Tep- } \\
\text { kisellik }\end{array}$ & $\begin{array}{l}\text { ÖÖİÖ-Ya- } \\
\text { kınlık }\end{array}$ & $\begin{array}{l}\text { ÖÖİÖ-Ça- } \\
\text { tışma }\end{array}$ \\
\hline $\mathrm{f}$ & 314 & 314 & 314 & 314 & 314 & 314 \\
\hline$X^{-}$ & 3.96 & 3.88 & 4.23 & 2.60 & 45.54 & 18.16 \\
\hline med & 4.00 & 3.85 & 4.28 & 2.55 & 45.67 & 18.01 \\
\hline $\bmod$ & 3.57 & 3.57 & 4.29 & 2.11 & 45.00 & 18.01 \\
\hline En Düşük & 1.57 & 1.14 & 2.57 & 1.00 & 36.00 & 12.00 \\
\hline En Yüksek & 6.00 & 5.86 & 6.00 & 4.56 & 55.00 & 31.00 \\
\hline ss & 0.95 & 0.97 & 0.75 & 0.78 & 3.43 & 3.99 \\
\hline Ranj & 4.43 & 4.71 & 3.43 & 3.56 & 19.00 & 19.00 \\
\hline Varyans & 0.90 & 0.94 & 0.56 & 0.61 & 11.76 & 15.99 \\
\hline Çarpıklık & -0.193 & -0.233 & 0.025 & 0.383 & -0.160 & 0.715 \\
\hline Basıklık & -0.477 & -0.427 & -0.500 & -0.529 & 0.131 & 0.245 \\
\hline
\end{tabular}

ÇiKMÖ=Çocuklar için Kısa Mizaç Ölçeği; ÖÖIÖ=Öğretmen-Öğrenci İlişki Ölçeği

Tablo 2. Değişkenlerin Ortalama, Standart Sapma ve Korelasyon Değerleri

\begin{tabular}{lllllllll}
\hline Değişkenler & $X^{-}$ & $S_{x}$ & 1 & 2 & 3 & 4 & 5 & 6 \\
\hline 1. ÇİKMÖ-Utangaçlı & 3.96 & 0.95 & 1 & & & & & \\
2. ÇİKMÖ-Sebatkârlık & 3.88 & 0.97 & -.030 & 1 & & & \\
3. ÇİKMÖ-Ritmiklik & 4.23 & 0.75 & $.126^{*}$ & $.348^{* *}$ & 1 & & \\
4. ÇİKMÖ-Tepkisellik & 2.60 & 0.78 & $-.112^{*}$ & $-.189^{* *}$ & $-.225^{* *}$ & 1 & & \\
5. ÖÖÖÖOÇatışma & 18.16 & 3.99 & $.131^{*}$ & $-.147^{* *}$ & -.095 & .003 & 1 & \\
6. ÖÖÏÖ-Yakınlık & 45.54 & 3.42 & .036 & $.245^{* *}$ & $.212^{* *}$ & -.101 & $-.163^{* *}$ & 1 \\
\hline
\end{tabular}
$N=314,{ }^{*} p<.05,{ }^{* *} p<.01$

ÇiKMÖ=Çocuklar için Kısa Mizaç Ölçeği; ÖÖIÖ=Öğretmen-Öğrenci İlişki Ölçeği 
Tablo 3. Çocuklar için Kısa Mizaç Ölçeği Alt Faktörleri Puanlarının Cinsiyete Göre Karşılaştırılmasına İlişkin Bağımsız Gruplar İçin T Testi Sonuçları

\begin{tabular}{llllllllll}
\hline Bağımlı Değişkenler & $\mathrm{C}$. & $\mathrm{N}$ & $\mathrm{X}$ & $\mathrm{Ss}$ & Ort. Farkt & $\mathrm{sd}$ & $\mathrm{p}$ & $\eta^{2}$ \\
\hline Utangaçlık & $\mathrm{K}$ & 168 & 3.92 & 0.93 & \multirow{2}{*}{0.07} & 0.627 & 312 & 0.521 & \\
& $\mathrm{E}$ & 146 & 3.99 & 0.98 & & & & & \\
Sebatkârlık & $\mathrm{K}$ & 168 & 4,01 & 0.99 & \multirow{2}{*}{0.28} & -2.622 & 312 & 0.009 & 0.02 \\
& $\mathrm{E}$ & 146 & 3,73 & 0.92 & & & & & \\
Ritmiklik & $\mathrm{K}$ & 168 & 4,19 & 0.77 & -0.09 & 1.076 & 312 & 0.283 & \\
Tepkisellik & $\mathrm{E}$ & 146 & 4,28 & 0.73 & & & & & \\
& $\mathrm{~K}$ & 168 & 2,56 & 0.79 & -0.09 & 1.059 & 312 & 0.291 & \\
\hline
\end{tabular}

Tablo 3'e göre Çocuklar için Kısa Mizaç Ölçeği alt faktörlerinden elde edilen puanlardan yalnızca sebatkârlık puanları ortalaması cinsiyete göre anlamlı olarak farklılaşmaktadır [ $\left.\mathrm{t}(312)=--2,622, \mathrm{p}<0.05, \eta^{2}=0.02\right]$. Kızların sebatkârlık puanları ortalaması ( $X=4.01)$ ile erkeklerin sebatkârlık puanları ortalaması $(X=3.73)$ incelendiğinde bu anlamlı farkın kızların lehine olduğu görülmektedir.

Tablo 4. Çocuklar için Kısa Mizaç Ölçeği Alt Faktörleri Puanlarının Anne Eğitim Durumuna Göre Karşılaştırılmasına İlişkin ANOVA Sonuçları

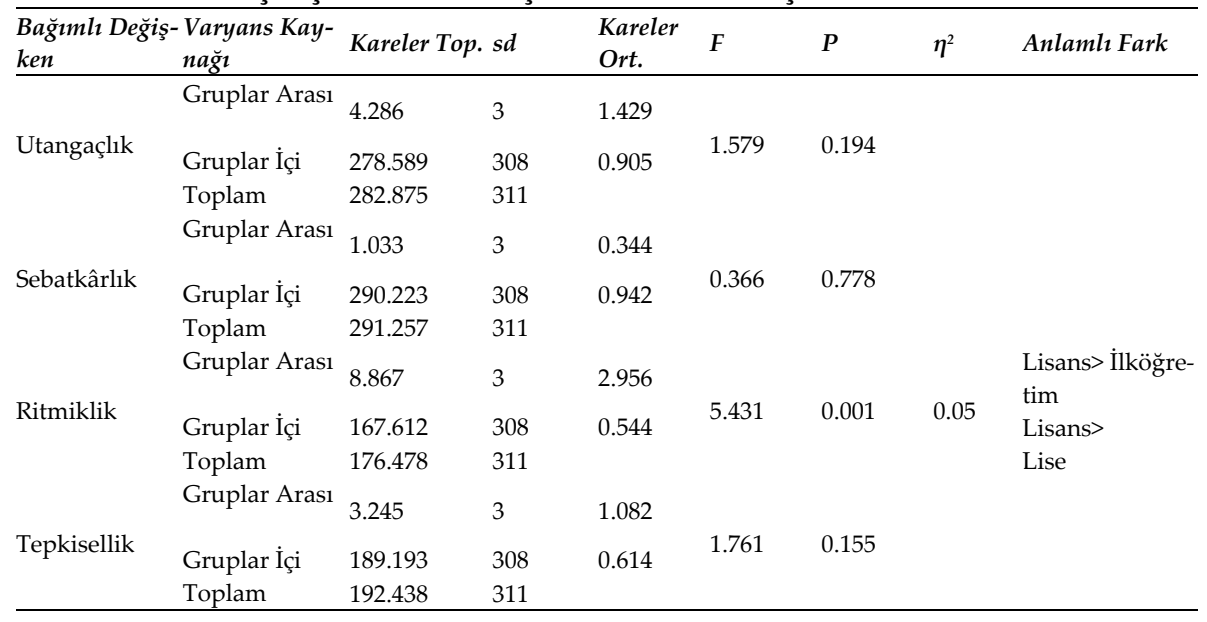

Tablo 4 incelendiğinde Çocuklar için Kısa Mizaç Ölçeği alt faktörlerinden yalnızca ritmiklik puanları ortalaması anne eğitim durumuna göre anlamlı olarak farklılaşmaktadır $\left[\mathrm{F}(3,308)=5.431, \mathrm{p}<0.05, \eta^{2}=0.05\right]$. Posthoc testi sonuçlarına göre bu anlamlı fark lisans-ilköğretim ile lisans-lise arasındadır. Anne eğitim durumu ilköğretim düzeyinde olan çocukların 
ritmiklik puanları ortalaması $(X=4.06)$ anne eğitim durumu lisans düzeyinde olanların ortalamasından $(X=4.39)$ anlamlı olarak daha düşüktür. Aynı şekilde anne eğitim durumu lise düzeyinde olan çocukların ritmiklik puanlarının ortalaması $(X=4.06)$ anne eğitim durumu lisans düzeyi olan çocukların ortalamasından $(X=4.35)$ anlamlı düzeyde daha düşüktür.

Tablo 5.Çocuklar için Kısa Mizaç Ölçeği Alt Faktörleri Puanlarının Baba Ĕ̆itim Durumuna Göre Karşılaştırılmasına İlişkin ANOVA Sonuçları

\begin{tabular}{|c|c|c|c|c|c|c|c|c|c|}
\hline Bağımlı Değişken & $\begin{array}{l}\text { Varyans Kay- } \\
\text { nağı }\end{array}$ & Kareler Top. & $S d$ & Kareler & & $F$ & $P$ & $\eta^{2}$ & $\begin{array}{l}\text { Anlamli } \\
\text { Fark }\end{array}$ \\
\hline & Gruplar Arası & 5.057 & 3 & 1.686 & & & & & \\
\hline \multirow[t]{3}{*}{ Utangaçlık } & Gruplar İçi & 273.757 & 303 & 0.903 & 1.866 & & 0.135 & & \\
\hline & Toplam & 278.813 & 306 & & & & & & \\
\hline & Gruplar Arası & 5.505 & 3 & 1.185 & & & & & \\
\hline \multirow[t]{3}{*}{ Sebatkârlık } & Gruplar İçi & 283.939 & 303 & 0.937 & 1.958 & & 0.120 & & \\
\hline & Toplam & 289.444 & 306 & & & & & & \\
\hline & Gruplar Arası & 4.781 & 3 & 1.594 & & & & & \\
\hline \multirow[t]{3}{*}{ Ritmiklik } & Gruplar İçi & 169.667 & 303 & 0.560 & 2.846 & & 0.038 & 0.03 & köŏretim \\
\hline & Toplam & 174.448 & 306 & & & & & & \\
\hline & Gruplar Arası & 3.565 & 3 & 1.188 & & & & & \\
\hline \multirow[t]{2}{*}{ Tepkisellik } & Gruplar İçi & 182.371 & 303 & 0.602 & 1.974 & & 0.118 & & \\
\hline & Toplam & 185.936 & 306 & & & & & & \\
\hline
\end{tabular}

Tabloya göre Çocuklar için Kısa Mizaç Ölçeği alt faktörlerinden ritmiklik puan ortalamaları baba eğitim durumuna göre anlamlı olarak farkl1laşmaktadır $\left[\mathrm{F}(3,303)=2.846, \mathrm{p}<0.05, \eta^{2}=0.03\right]$. Çocukların ritmiklik alt ölçeğinden elde ettikleri puanlar karşılaştırıldığında babası lisans mezunu olan çocukların ortalama puanları $(X=4.36)$ babası ilköğretim mezunu olan çocukların ortalama puanlarından $(X=4.05)$ manidar düzeyde daha yüksektir.

Öğretmen-Öğrenci İlişki Ölçeğinden elde edilen veriler ile Çocuklar için Kısa Mizaç Ölçeğinin alt faktörleri arasındaki ilişki Pearson momentler Çarpımı korelasyon katsayısı ile incelenmiştir. Sonuçlara göre Öğretmen-Öğrenci İlişkisi Ölçeği ile mizaç ölçeğinin alt faktörlerinden olan utangaçlık arasındaki ilişki 0.133 olarak bulunmuştur ve bu düşük düzeydeki ilişki anlamlıdır ( $\mathrm{p}<0.05)$. Öğretmen-Öğrenci İlişkisi Ölçeği ile Çocuklar İçin Kısa Mizaç Ölçeğinin geriye kalan sebatkârlık, ritmiklik ve tepkisellik alt faktörleri arasında anlamlı düzeyde bir ilişkiye rastlanmamıştır.

Mizaç ölçeği alt faktörleri öğretmen öğrenci ilişkisi ölçeğinden elde edilen puanları anlamlı olarak yordamaktadır. 
Öğrenci-Öğretmen İlişkisi = 2,335 + 0.023.Utangaçlık + 0.023.Sebatkârlık + 0.034.Ritmiklik + 0.044.Tepkisellik

Tablo 6. Sebatkârlık ve Ritmikliğin Yakınlığı Yordayıcılı̆̆ına İlişkin Regresyon Analizi Sonucu

\begin{tabular}{|c|c|c|c|c|c|c|c|}
\hline Değişken & $B$ & Standart Hata & $\beta$ & $t$ & $p$ & İkili $r$ & Kısmi R \\
\hline Sabit & 40,348 & 1,674 & & 24,103 & 000 & & \\
\hline Sebatkârlık & 0,681 & 0,208 & 0,193 & 3,272 & ,001 & 0,245 & 0,183 \\
\hline Ritmiklik & 0,618 & 0,272 & 0,136 & 2,275 & ,024 & 0,212 & 0,128 \\
\hline$R=0,283$ & $R^{2}=($ & & & & & & \\
\hline$F=6,712$ & $p<0$ & & & & & & \\
\hline
\end{tabular}

Çocuklar için Mizaç Ölçeğinin alt boyutlarının Öğretmen-Öğrenci İlişkisi Ölçeği alt boyutu olan yakınlığı yordama durumları incelenmiştir. Buna göre sebatkârlık ve ritmiklik yakınlığı anlamlı olarak yordamaktadır $\left(\mathrm{R}^{2}=0,080, \mathrm{p}<0.05\right)$. Tablo 6 incelendiğinde, sebatkârlık ve ritmiklik arasında yakınlığı en iyi yordayan değişken sebatkârlık ( $\beta=.193$ ), ikinci yordayan değişkenin ise ritmiklik ( $\beta=.136)$ olduğu görülmektedir. Sebatkârlık ve ritmiklik birlikte yakınlığın toplam varyansının \%8'ini açılamaktadır. Çocuklar için Mizaç Ölçeğinin diğer alt boyutları olan utangaçlık ve tepkisellik yakınlığı anlamlı olarak yordamadığı için analizden çıarılmıştır.

Tablo 7. Utangaçlık ve Sebatkârlığın Çatışmayı Yordayıcılı̆̆ına İlişkin Regresyon Analizi Sonucu

\begin{tabular}{llllllll}
\hline Değişken & $B$ & Standart Hata & $\beta$ & $t$ & $p$ & Ikili $r$ & Kısmi $R$ \\
\hline Sabit & 19,959 & 1,991 & & 10,025 &, 000 & & \\
Utangaçlık & 0,562 & 0,238 & 0,134 & 2,365 &, 019 & 0,131 & 0,133 \\
Sebatkârlık & $-0,502$ & 0,248 & $-0,122$ & $-2,028$ &, 043 & $-0,147$ & $-0,115$ \\
\hline
\end{tabular}

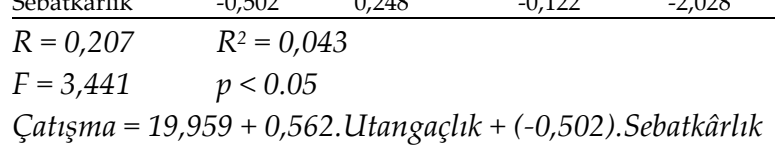

Öğretmen-Öğrenci İlişki Ölçeği alt boyutları ile Çocuklar için Kısa Mizaç Ölçeğinin alt boyutları arasındaki ilişki Pearson momentler Çarpımı korelasyon katsayısı ile incelenmiş ve sonuçlar Tablo 7'de gösterilmiştir. Sonuçlara göre Öğretmen-Öğrenci İlişki Ölçeği alt boyutlarından olan çatışma ile Çocuklar için Kısa Mizaç Ölçeği alt boyutlarından utangaçlık $(\mathrm{r}=.131)$ arasında pozitif yönde zayıf, sebatkârlık ( $\mathrm{r}=-.147)$ arasında negatif 
yönde zayıf ilişkiye rastlanmıştır. Bu iki yordayan değişkenden çatışmayı birinci sırada yordayan değişkenin utangaçlık $(\beta=.134)$, ikinci sırada yordayan değişkenin sebatkârlık ( $\beta=-$.122) olduğu görülmektedir. ÖğretmenÖğrenci İlişki Ölçeği alt boyutlarından bir diğeri olan yakınlık ile sebatkârlık ( $\mathrm{r}=.245)$ ve ritmiklik $(\mathrm{r}=.212)$ arasında pozitif yönde zayıf düzeyde ilişki olduğu görülmektedir.

Çocuklar için Mizaç Ölçeğinin alt boyutlarından utangaçlık ve sebatkârlık Öğretmen-Öğrenci İlişkisi Ölçeği alt boyutu olan çatışmayı anlamlı olarak yordamaktadır $\left(R^{2}=0,043, p<0.05\right)$. Utangaçlık ve sebatkârlık birlikte çatışmanın toplam varyansının \%4'ünü açıklamaktadır. Çocuklar için Mizaç Ölçeğinin diğer alt boyutları olan ritmiklik ve tepkisellik çatışmayı anlamlı olarak yordamadığından analizden çıkarılmıştır.

\section{Sonuç ve Tartışma}

Çalışmanın sonuçlarından biri olarak çocukların mizacının cinsiyet değiş̧kenine etkisine bakıldığında, sebatkarlık alt boyutu dışında diğer alt boyutlarda anlamlı bir farklılık bulunamamıştır. Sebatkarlık alt boyutunda ise ortaya çıkan anlamlı farklılığın kızların lehine olduğu görülmektedir. Çocukların büyüme sürecinde toplum tarafından onlardan farklı roller beklenmektedir (Yağmurlu ve ark. 2005). Bu rollerden biri olarak kız çocuklarının toplum tarafından daha sebatkar olmalarının beklenmesi çıkan sonucu açıklayabilir. Akbas, (2016), Walker, Berthersen ve Irwing (2001), Erdinç'in (2009) çalışmalarında da benzer şekilde sebatkarlık alt boyutu ile cinsiyet arasında kızların lehine anlamlı sonuçlar bulunmuştur. Yapılan bir çalışma sonucunda ise mizaç ile cinsiyet değişkeni arasında anlamlı farklılıklar bulunmamıştır (Bryan, Dix, 2009). Araştırma sonuçlarında ç1kan bu farklılıklar kültürel olarak bireylerden farklı beklentilerin olması ve cinsiyetlere farklı rollerin verilmesi şeklinde açıklanabilir.

Çalışma bulgularından bir diğeri de anne eğitimi lisans düzeyinde olan çocukların mizaç özelliklerinden ritmiklik alt boyutu, anne eğitim düzeyi lise ve ilköğretim düzeyinde olan annelere göre daha yüksektir. Özdemir (2017)'in yaptığı tez çalışması sonuçların da benzer şekilde lisansüstü öğrenim düzeyine sahip annelerin çocuklarının ritmiklik ve sebatkarlık alt boyutlarında en yüksek düzeyde olduğunu bulmuştur. Yapılan bir diğer 
çalışma sonucunda annenin eğitim durumu çocukların tüm mizaç özellikleriyle ilişkili bulunmuştur. Çocukların mizaç özelliklerinin tümünnde anne eğitim düzeyinin yüksek olması aracılık etmiştir (Bornstein, Hahn, Putnich ve Pearson, 2019).

Çalışmanın bir diğer sonucuna göre çocuğun mizaç özelliklerinden ritmiklik alt boyutu babanın öğrenim durumuna göre farklılaşmaktadır. $\mathrm{Bu}$ sonuçla benzer şekilde Özdemir' in (2017) yaptığı araştırma sonucunda babaların öğrenim düzeyi yükseldikçe sıcakkanlılık ve ritmiklik alt boyutlarının da arttığını ortaya koymuştur. Purwati ve Japar'ın (2017) yaptıkları araştırma sonucunda da ebeveyn eğitim durumuyla mizaç ilişkili bulunmuştur. Çalışmanın sonuçlarında, mizaç faktörünün 0,619 korelasyona sahip olup eğitim düzeyi olan 0,491'den daha yüksek olduğu bulunmuştur.

$\mathrm{Bu}$ araştırmanın sonuçlarına göre sebatkârlık ve ritmiklik öğretmenöğrenci iliş̧kisi alt boyutundan yakınlığı anlamlı olarak yordamaktadır. Bu sonuçla benzer şekilde Seo ve Lee'nin (2012) yaptığı araştırmaya göre aktif mizacın öğretmen-öğrenci ilişkisinin yakınlık alt boyutu ile bağımsız etkileri bulunmuş ve bu toplam varyansın \%12'sini açıklamaktadır.

Bu çalışmadan çıan bir diğer sonuç da utangaçlığın çatışmayı pozitif yönde ve sebatkarlığın ise çatışmayı negatif yönde yordadığıdır. Bu sonuç mizaç özelliklerinden utangaç olan çocukların düşük öğretmen yakınl1ğında negatif ilişki içinde bulunduğunu göstermektedir. Bu sonuç Çinli (Han vd., 2016) ve İtalyan okul öncesi çocuklarla (Sette vd., 2014) yürütülen önceki çalışmalarla uyumludur; bu, çocukların utangaçlı̆̆ının, öğretmen yakınlığının daha düşük seviyelerine sahip olduklarında sosyal yeterlilik ile olumsuz bir şekilde ilişkili olduğunu gösterir, bu durum öğretmen ve çocuklar arasındaki mücadelenin göstergesi olabilir. Seo ve Lee'nin (2012) yaptıkları çalışmada, çocukların aktif mizaç ile çatışma alt boyutu arasında pozitif yönde bir ilişki olduğunu bulunurken yakınlık alt boyutunda bir ilişki bulunmamıştır. Ören ve Jone'un (2009) yaptığı çalişma sonucuna göre çocukların mizacıyla öğretmen-çocuk ilişkisi alt boyutları arasında yüksek düzeyde ilişki bulunmuştur.

Araştırmadan elde edilen sonuçlar doğrultusunda bazı öneriler getirilmiştir.

- Mizaç ve öğretmenlik arasındaki etkileşimi daha iyi anlamak ve öğretmenin çocuğun mizacına uygun yaklaşımı belirlemesinde 
yararlı yollar bulabilmesi amacıyla konuyla ilgili farklı örneklemlerle çalışmalar yapılabilir.

- Bu çalışma planlanırken uyarlaması yapılmış mizaç ile ilgili ölçme araçlarının sınırlı olduğu görülmüştür. Çocukların mizacına dair ölçme aracı uyarlama çalışmaları yapılabilir.

- $\quad \mathrm{Bu}$ araştırmada pandemi koşulları nedeniyle çocuklarla ilgili veriler öğretmenler ve ebeveynler aracılığıyla toplanmıştır. Veri toplama kaynakları olarak bunların yanı sıra, çocuğun doğal ortamlarda gözlemlenmesi çocuğa ilişkin daha anlamlı sonuçlar almayı sağlayabilir. 


\section{EXTENDED ABSTRACT \\ Investigation of Temperament in Preschool Child- ren in terms of Predicting Level of Teacher-Student Relationship and Some Variables \\ Sabiha Eren \\ Uşak University}

\section{Introduction}

Better social outcomes for children are achieved when teachers develop positive interactions with children at risk in terms of temperament, such as high closeness and low conflict, by providing loving and supporting surroundings (Rudasill et al., 2013). Early relationships between children and their teachers are crucial in the development of social competence. Positive teacher-child relationships, for example, can safeguard vulnerable young children from negative social interactions (Acar et al., 2018). Children's poor connections with their teachers, on the other side, can influence their troublesome behavior with their peers. Low levels of intimacy and high levels of conflict between teachers and students can exacerbate the links between shyness and social competence or aggressive behavior among peers. In a study of Italian preschool classrooms, Sette et al. (2014) discovered that shyness was adversely connected to teacher-graded social competence and favorably related to teacher-graded social competence. For example, Sette et al. (2014), in their study in Italian preschool classrooms, found that shyness was negatively related to teacher-grade social competence and positively related to peer rejection for children with low teacher closeness.

\section{Purpose and Importance}

Developmental psychology provides a valuable framework for original research and interactions between outcomes and contributors that contribute to the problem. Different techniques to evaluating the child's interactional results were determined in this study. The first of them is the 
teacher-child relationship, which is one of the child's interactions with the environment, as previously mentioned. According to the existing literature, the child's temperament features will influence the closeness and conflict in the teacher-child relationship.

The purpose of this study is to look at the predictors of temperament and teacher-child relationships in children aged 4-6 who attend pre-school education facilities, as well as to see if temperament sub-dimensions differ depending on parental education level and gender. The ethical approval was obtained by an ethics committee. Answers to the following questions were sought in this context:

1. The average scores obtained from the children's temperament subtests,

Is it different

based on gender

mother's educational qualifications

depending on the father's educational level?

2. Can the teacher-child relationship be predicted by a child's temperament?

\section{Method}

The study group consists of the parents and teachers of 314 children, 168 of whom are girls, and 146 are boys. The study data were collected from kindergartens, nursery classes, and private schools affiliated with the Ministry of National Education in Uşak's city center during the spring semester of the 2020-2021 academic year.The Children's Short Temperament Scale and the teacher-student relationship scales were used to collect data.Descriptive statistics, independent sample t-test, ANOVA, and regression analysis were used in the analysis of the data. According to the results of the research, a relationship was found between the temperament, gender, and educational status of parents.

\section{Conclusion And Recommendations}


When the effect of children's temperament on the gender variable was evaluated, no significant differences were identified in other sub-dimensions except persistence, according to one of the study's findings. On the other hand, there is a considerable difference in favor of the females in the sub-dimension of persistence. In the development of children, society expects different roles (Yağmurlu et al. 2005). In the case of one of these roles, society's expectation of girls to be more persistence may explain the outcome. Similarly, substantial results in favor of girls were discovered between the persistence sub-dimension and gender in the investigations of Akbaş (2016), Walker, Berthersen, and Irwing (2001), and Erdinç (2009). According to the findings of a study, temperament and gender have no significant differences (Bryan, Dix, 2009). These discrepancies in research findings can be attributed to cultural variations.

Another finding of the study is that the rhythmicity sub-dimension, which is one of the temperament characteristics of children whose mothers have completed college, is higher than that of children whose mothers have completed high school or primary school. The results of the thesis study were identical in the rhythmicity and persistence sub-dimensions of the children of mothers with graduate education, according to Özdemir (2017). Another study discovered that the mother's educational status was linked to all of the children's temperament features. All temperamental features of children were mediated by the high level of parental education (Bornstein, Hahn, Putnich, \& Pearson, 2019).

Another finding of the study is that the rhythmicity sub-dimension, which is one of the child's temperament characteristics, varies depending on the father's educational position. Similar to this finding, Özdemir (2017) discovered that as dads' educational levels rise, the sub-dimensions of approach and rhythmicity rise as well. Purwati and Japar (2017) discovered a link between parental education and disposition in their study. The temperament element exhibited a correlation of 0.619 , which was higher than the education level of 0.491 , according to the study's findings.

According to the findings of this study, persistence and rhythmicity significantly predict closeness in the sub-dimension of the teacher-student relationship. Similar to this finding, Seo and Lee (2012) discovered that 
active temperament has independent effects on the closeness sub-dimension of the teacher-student relationship, accounting for $12 \%$ of the total variance.

Another finding from this study is that shyness positively predicts conflict and persistence negatively predicts conflict. This finding indicates that children who are fearful of temperament traits have a negative relationship with low teacher closeness. This finding is consistent with previous research on Chinese (Han et al., 2016) and Italian preschool children (Sette et al., 2014); it suggests that children's shyness is negatively associated with social competence when they have lower levels of teacher intimacy, which may indicate a struggle between the teacher and the children. Seo and Lee (2012) discovered a positive relationship between children's active temperament and the conflict sub-dimension, but no relationship was found in the closeness sub-dimension. According to the findings of Ören and Jone's (2009) study, there is a strong correlation between children's temperament and the sub-dimensions of the teacher-child relationship.

Some recommendations were made in light of the research findings.

- Studies on the subject can be conducted with various samples to better understand the interaction between temperament and teaching and to help teachers find useful ways to determine the appropriate approach for the child's temperament.

- While this study was being planned, it was discovered that the temperament measurement tools that had been adapted were limited. It is possible to modify the measurement tool to account for the temperament of children.

- Due to pandemic conditions, this study's data on children was gathered through teachers and parents.

- Observing the child in natural environments, in addition to these data collection sources, can provide more meaningful results about the child. 


\section{Kaynakça / References}

Acar, I. H., Kutaka, T. S., Rudasill, K. M., Torquati, J. C., Coplan, R. J. ve Yıldız, S. (2018). Examining the roles of child temperament and teacher-child relationships as predictors of Turkish children's social competence and antisocial behavior. Current Psychology, 39(6), 2231-2245. https://doi.org/10.1007/s12144-018-9901-z.

Akbas, B. (2016). Okul ö̈cesi egittim kurumuna devam eden 60 ay ve ü̈eri çocuklarm sosyal uyum becerileri ile mizaç, ozzellikleri arasındaki ilisskinin incelenmesi. Yuiksek lisans tezi. Aksaray Universitesi, Sosyal Bilimler Enstitüsü, İlköğretim Ana Bilim Dalı, Aksaray.

Bee, H., Dennis, B. (2009). Çocuk gelişim psikolojisi. (çev. Okhan Gündüz), İstanbul: Kaknüs Yayınları.

Bornstein, M. H., Hahn, C. S., Putnick, D. L. ve Pearson, R. (2019). Stability of child temperament: Multiple moderation by child and mother characteristics. British Journal of Developmental Psychology, 37(1), 51-67.

Côté, S. M., Vaillancourt, T., Barker, E. D., Nagin, D. ve Tremblay, R. E. (2007). The joint development of physical and indirect aggression: Predictors of continuity and change during childhood. Development and Psychopathology, 19, 37-55. doi 10.1002/ab.20313.

Denham, S. A. (2006). Social-emotional competence as support for school readiness: What is it and how do we assess it? Early Education and Development. Special Issue: Measurement of School Readiness, 17, 57-89.

Dollar Jessica M., Perry, Nicole B., Calkins, Susan D., Keane, Susan P. and Shanahan Lilly. (2018). Temperamental anger and positive reactivity and the development of social skills: Implications for academic competence during preadolescence. Early Educ Dev., 29(5), 747-761. doi:10.1080/10409289.2017.1409606.

Doumen, S., Verschueren, K., Buyse, E., Germeijs, V., Luyckx, K. ve Soenens, B. (2008). Reciprocal relations between teacher-child conflict and aggressive behavior in kindergarten: A three-wave longitudinal study. Journal of Clinical Child \& Adolescent Psychology, 37(3), 588-599. doi 10.1080/15374410802148079.

Erdinc, S. (2009). Okul ö̈cesi dö̈em çocuklarında fiziksel ve iliş,kisel saldırganlığn çeşitli degiss,kenler açısından incelenmesi. Yuksek lisans tezi. Ankara Universitesi, Eğitim Bilimleri Enstitü, Okul Öncesi Eğitim Bilim Dalı, Ankara. 
Flynn, B. M. (2000). The teacher-child relationship, temperament, and coping in children with developmental disabilities. Doctoral Dissertation. Teachers College, Columbia University. (UMI Number: 9979194).

Gresham, F. M., Elliott, S. N., Vance, M. J. and Cook, C. R. (2011). Comparability of the social skills rating system to the social skills improvement system: content and psychometric comparisons across elementary and secondary age levels. School Psychology Quarterly, 26(1), 27-44.

Han, P. G., Wu, Y. P., Tian, Y., Xu, M. X. ve Gao, F. G. (2016). The relationship between shyness and externalizing problem in Chinese preschoolers: The moderating effect of teacher-child relationship. Journal of Education and Training Studies, 4(3), 167-173. https:// doi.org/10.11114/jets.v4i3.1295.

Khatibi M, Khormaee F. (2016). Biological Basis of Personality: A Brief Review. J. Life Sci. Biomed. 6(2), 33-36.

Keogh, B. K. ve Burstein, N. D. (1988). Relationship of temperament to preschoolers' interactions with peers and teachers. Exceptional Children, $54,456-561$.

Ladd, G. W. ve Birch, S. H. (1999). Children's social and scholastic lives in kindergarten: Related spheres of influence? Child Development, 70(6), 1373-1400.

Ladd, G. W., Kochenderfer, B. J. ve Coleman, C. C. (1996). Friendship quality as a predictor of young children's early school adjustment. Child Development, 67, 1103-1118.

Lane, K. L., Givner, C. C. ve Pierson, M. R. (2004). Teacher expectations of student behavior: Social skills necessary for success in elementary school classrooms. Journal of Special Education, 38, 104-111.

Mashburn, A. J. ve Pianta, R. C. (2006). Social relationships and school readiness. Early Education and Development, 17, 151-176.

Masten, A. S. (2006). Developmental psychopathology: Pathways to the future. International Journal of Behavioral Development, 31, 46-53.

Merrell, K.W. (1993). Using behavior rating scales to assess social skills and antisocial behavior in school settings: Development of the school social behavior scales. School Psychology Review, 22(1), 115-134.

Oren, M. ve Jones, I. (2009). The relationships between child temperament, teacher-child relationships, and teacher-child interactions. International Education Studies, 2(4), 122-133. 
Özdemir, A.N. (2017) Okul öncesi dönem çocuklarının akran șiddetine maruz kalma düzeyi, mizac, tarzı ve empatik becerilerinin incelenmesi.Yüksek Lisans Tezi. Gazi Üniversitesi, Eğitim Bilimleri Enstitü, Okul Öncesi Eğitimi Bilim Dalı, Ankara.

Purwati, P., \& Japar, M. (2017). Parents' education, personality, and their children's disruptive behaviour. International Journal of Instruction, 10(3), 227-240. https://doi.org/10.12973/iji.2017.10315a.

Pianta, R. C. (1999). Enhancing relationships between children and teachers. Washington, DC: American Psychological Association.

Pianta, R. C. (2001). STRS: Student-teacher relationship scale: Professional manual. Psychological Assessment Resources.

Rose-Krasnor, L. ve Denham, S. (2009). Social-emotional competence in early Childhood In K. H. Rubin, W. M. Bukowski, \& B. Laursen (Eds.), Handbook of Peer Interactions, Relationships, and Groups (p.162-179). New York, NY: The Guildford Press.

Rudasill, K. M. ve Rimm-Kaufman, S. E. (2009). Teacher-child relationship quality: The roles of child temperament and teacher-child interactions. Early Childhood Research Quarterly, 24(2), 107-120

Sanson, A., Hemphill, S. A., \& Smart, D. (2004). Connections between temperament and Social Development: A Review. Social Development, 13(1), 142-170. https://doi.org/10.1046/j.1467-9507.2004.00261.x.

Scott, T. M. ve Nelson, C. M. (1999). Using functional behav- ioral assessment to develop effective intervention plans: Practical classroom application. Journal of Positive Behavior Interventions, 1, 242-251.

Séguin, D. G. ve MacDonald, B. (2018). The role of emotion regulation and temperament in the prediction of the quality of social relationships in early childhood. Early child development and care, 188(8), 1147-1163.

Silver, R. B., Measelle, J. R., Armstrong, J. M. ve Essex, M. J. (2005). Trajectories of classroom externalizing behavior: Contributions of child characteristics, family characteristics, and the teacher-child relationship during the school transition. Journal of School Psychology, 43(1), 39-60.

Shiner, R. L. (2005). The impact of temperament on child development: Comments on Rothbart, Kagan, and Eisenberg. Encyclopedia on Early Childhood Development https://www.researchgate.net/publication/237588749_The_Impact_of_Temperament_on_Child_Development_Comments_on_Rothbart_Kagan_and_Eisenberg. 15.12.2021 tarihinde erişim sağlanmıştır. 
Silver, R. B., Measelle, J., Armstrong, J. M. and Essex, M. J. (2005). Trajectories of classroomexternalizing behavior: Contributions of child characteristics, family characteristics, and theteacher-child relationships during the school transition. Journal of School Psychology, 43(1), 39-60.

Stuhlman, M. W. ve Pianta, R. C. (2002). Teachers' narratives about their relationships with children: Associations with behavior in classrooms. School Psychology Review, 31, 148-163.

Thomas, A., Chess, S., Birch, H. G., Hertzig, M. E. ve Korn, S. (1963). Behavioural individuality in early childhood. New York: New York University Press.

Thomas, A., Chess, S. ve Birch, H.G. (1968). Temperament and behavior disorders in children. New York: New York University Press.

Van Lier, P. A. C. ve Koot, H.M. (2010). Developmental cascades of peer relations and symptoms of externalizing and internalizing problems from kindergarten to fourth-grade elementary school. Development and Psychopathology, 22, 569-582. doi 10.1017/S0954579410000283.

Walker, S., Berthelsen, A. ve Irving, K. (2001). Temperament and peer acceptance in early childhood: Sex and social status differences. Child Study Journal, 31(3), 177-192.

Yagmurlu, B., Sanson, A. ve Köymen, S.B. (2005) Ebeveynlerin ve çocuk mizacının olumlu sosyal davranış gelişimine etkileri: Zihin kuramının belirleyici rolü. Türk Psikoloji Dergisi, 20(55), 1-20.

Yagmurlu, B. ve Sanson, A. (2009). The role of child temperament, parenting and culture in the development of prosocial behaviors. Australian Journal of Psychology, 61, 77-88.

\section{Kaynakça Bilgisi / Citation Information}

Eren, S. (2021). Okul öncesi çocuklarda mizacın öğretmen-öğrenci ilişkisini yordama düzeyi ile bazı değişkenler açısından incelenmesi. OPUS-Uluslararası Toplum Araştırmaları Dergisi, 18(44), 7795-7817. DOI: $10.26466 /$ opus.966493. 